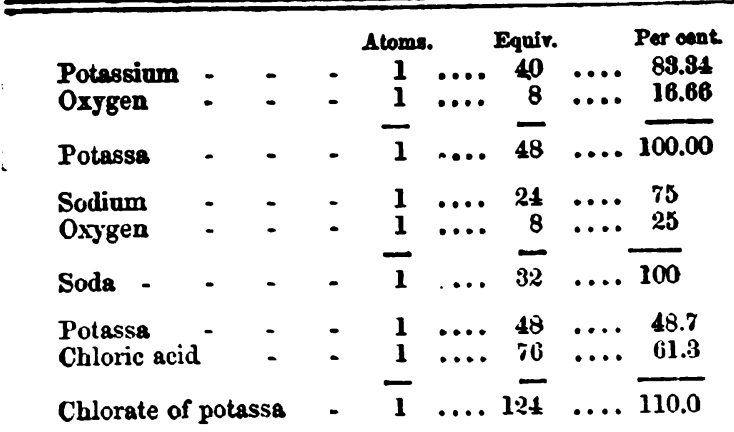

Then, as chloric acid consists of one atom of chlorine and five atoms of oxygen, we must necessarily have six atoms of oxygen, combining with one atom of potassium and one atom of chlorine, to form chlorate of potassa.

\begin{tabular}{|c|c|c|c|c|c|c|c|c|}
\hline $\begin{array}{l}\text { Carbon } \\
\text { Hydrogen } \\
\text { Oxygen }\end{array}$ & - & - & & $\begin{array}{c}\text { Atoms. } \\
4 \\
3 \\
5\end{array}$ & $\begin{array}{l}\ldots \\
\ldots \\
\ldots\end{array}$ & $\begin{array}{c}\text { Equiv. } \\
24 \\
3 \\
40\end{array}$ & $\begin{array}{l}\cdots \\
\cdots \\
\cdots\end{array}$ & $\begin{array}{c}\text { Per cent } \\
35.8 \\
4.5 \\
50.7\end{array}$ \\
\hline Citric acid & - & - & & 1 & $\cdots$ & 67 & .. & 100.0 \\
\hline $\begin{array}{l}\text { Carbon } \\
\text { Hydrogen } \\
\text { Oxygen }\end{array}$ & - & - & - & $\begin{array}{l}4 \\
3 \\
3\end{array}$ & $\begin{array}{l}\cdots \\
\cdots \cdots\end{array}$ & $\begin{array}{r}24 \\
3 \\
24\end{array}$ & $\begin{array}{l}\cdots \\
\cdots \\
\cdots\end{array}$ & $\begin{array}{r}47.00 \\
5.88 \\
47.00\end{array}$ \\
\hline Acetic acid & & & & 1 & $\cdots$ & 51 & $\cdots$ & 100.00 \\
\hline $\begin{array}{l}\text { Carbon } \\
\text { Hydrogen } \\
\text { Oxygen }\end{array}$ & - & - & 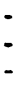 & $\begin{array}{l}4 \\
2 \\
5\end{array}$ & $\begin{array}{l}\cdots \\
\cdots \\
\cdots\end{array}$ & $\begin{array}{r}24 \\
2 \\
40\end{array}$ & $\begin{array}{l}\cdots \\
\cdots \\
\cdots\end{array}$ & $\begin{array}{r}36.1 \\
8.0 \\
60.6\end{array}$ \\
\hline arts & & & - & 1 & $\cdots$ & 66 & -... & 100.0 \\
\hline
\end{tabular}

The combination of any of these acids with potassa or soda forms a neutral salt, containing a llarge amount of oxygen, which doubtless acts upon the blood in a similar manner to that which has been explained; but these salts do not part with their oxygen as readily as the mineral acids, and are of no service in the premonitory diarrhoen.

This leads us to the "mechanical effect", as the astringent action of the nitro-sulphuric acid has been termed, and which differs merely in degree from that which is produced by the vegetable astringents. In all these latter substances, tannic acid is the active principle; and this being rich in oxygen, readily enters into combination with the various tissues, or more particularly with the albumen and fibrin contained in them-the same process taking place to a limited extent in the living body as occurs during the conversion of an animal's skin into leather. Albumen being an alkaliue body, it is necessary that its alkali should be neutralised before any change of this nature can take place: the tannic acid then combines with the albumen as a base, and tannate of albumen is the result. It is, however, certain, that the oxygen plays an important part during this process; or why should this body (i.e., tannic acid, the very best adapted to its purpose) contain such a large proportion of this element?

Whether the theory here propounded be correct or not, it is quite certain that practice, both in this country and on the continent, has shown the utility of the mineral acids; and although, like all other remedies, they are unfortunately not infallible, nevertheless, they are about the best we can employ. In a large number of casual cases of diarrhoea, lately applying for relief, as well as many others which have occurred under my own treatment at the St. George's and St. James's Dispensary, this remedy has proved speedily effective with some very few exceptions; the diarrhoea and vomiting have ceased, and griping and cramps, when present, have been almost immediately removed. Emboldened by the success of this treatment in the adult, I have tried the same plan with children, and found it answer beyond my warmest expectation : it does not, however, act beneficially upon children at the breast; I suppose, on account of its decomposing the milk in the stomach, and thus tonding to keep up irritation; bat, providing the child is not sucking, it matters not ho young it is, the remedy has just the same effect $a$ in the adult, relieving the griping, and stopping the purging and sickness.

16, Welbeck Street, Carendish Square, Oct. 25th, 1859.

\section{THE CONDITION OF THE FETAL HEAD AT THE FULL PERIOD OF GESTATION, AND ITS EFFECTS ON PARTURITION.}

\author{
By GEORGE KING, Fisq. \\ [Read at the Meeting of the Bath and Bristol Branch, \\ September 29, 1853.]
}

Trie state of the foetal head in utero may be considered rather an uninteresting and obscure subject for discussion; but it is one that may cause us much anxiety and trouble, as well as difficulty in practice. It is a subject, it seems to me, that has not been noticed, or has not attracted that attention among the professors in midwifery that it ought, and which I consider its importance deserves.

As there are various distortions and different dimensions of the female pelvis, so there may be, and often is, a great. diversity as to the character and condition, as well as disproportion in the size, of the fœetal skull; and it is to this unusual development and altered state of the foetal craniumthat I wish to direct the attention of the meeting, as I consider it to be a matter of much interest to us all. But to the obstetric practitioner it is of vital importance; and it has often appeared to me strange that it should have been. so little noticed by authors and lecturers. It is this apparent neglect that has induced me to bring the subject before the members of the Association. I think that it is Smellie. who says: "That difficult labours may proceed from circumstances belonging to the child that is to be born, from theextraordinary size of the body, or any part of it, from its. being unable to facilitate the birth."

On trying a pain at the commencement of labour, if the membrancs are ruptured we generally expect to find the fotal head presenting, giving the sensation of a smooth conical body, more cartilaginous or osseo-cartilaginous, and yielding, but not bony. It is also sometimes found to be hard, compact, firm, and highly ossified, and unyielding; and it is to this unusual state or texture, and want of uniformity in the cranium bones of the fotus, and its influence in connexion with parturition that $I$ am anxious to draw attention. To the accoucheur, the condition of the footal head at the commencement of labour is of the first importance, as it enables him to judge of the progress, and to form some idea as to the result of the labour.

In the cases to which I would now draw attention, the head will still be found within the cavity of the uterus, and the vertex generally presenting; and, from its hard and firm state, however strong the pains may be, its full rotundity would be retained, and the effect would be the expansion of the neck of the uterus, not the expulsion of the child. Such a head may also be found without the cavity of the utcrus, resting on the brim of the pelvis; and if the action of the uterus has been frequent and strong, and suffered to go on until its expulsive powers are exhausted and the patient restless and irritable, we may expect to find on examination, some puffing or a pouch of the scalp presenting; but this long and continued uterine action we shall find has made no impression on the fotal cranium. Having made ourselves acquainted with the condition of the head, we ought never to allow such a waste of time and labour, and such annoying symptoms to be produced, while we have the means of preventing it by removing the cause. This ineffectual action of the uterus is the cause of those laborious and lingering labours which tend to that depression of the mental energy, and exhaustion of the physical powers of the patient, which often are so trying and annoying to the medical attendant, while the head of the child is endearouring to adapt itself to the superior outlet of the 
pelvis. This high degree of ossification of the cranial bones of tho fatus, I believe, more frequently renders the operation of craniotomy and destruction of the child necessary, than does contraction or deformity of the pelvis; and with such a condition of the child's head, no natural uterine action, with all the auxiliary assisting muscular power of the abdominal muscles, could ever force it into the cavity of the pelvis, even if there were no contraction nor deformity; there would, therefore, be every moral certainty that the child could not be born alive, and that some assistance must be rendered to effect the delivery. To allow such an ineffectual sacritice of the natural powers to continue without interference, would be risking the mother's life. In such a case, the forceps would be of no use, for it would be utterly impossible to compress such a head within their grasp, even if the head could be reached.

Turning, in cases of deformity of the pelvis, when it is considered impossible for the heal to pass, has lately been recommended. This practice, I fear, would only be adding to the difficulty and render the case more complicated. If this mode of treatment is ever snecessful, it will be in consequence of the easy vielding and adaptability of the fotal head to the contracted outlet, and if the delivery could not be completed in this way, the opening of the foetal head above the brin of the pelvis, while the body is lying in the vaginal passage, would be, I beliere, impossible, without doing some serious injury to the mother. With the vaginal passage thus blocked up, I have yet to learn how the hand and arm of the operator are to be introduced to the superior outlet of the jelvis to direct the perforating and bringing down the foetal head. And surcly no man would have the hardihood to perform such an operation without such a guide and director.

The only remedy then, and, I believe, the only practice to be adopted is embryotomy; and, howerer revolting and painful to our feelings it may be to perform such an operation, it must be done, and quickly too, or the mother's life would be lost. In natural labours, passireness and patience should be our motto; in preternatural ones, it should be promptness and performance. Nost of the untoward circumstances and serious consequences that follow preternatural labours, arise from delaying, too long, what ought to have been done at once. In this condition of the child's head, it is very clear that craniotomy is our only resource; but it is not so easy a matter to perform this operation under the circumstances as some would imagine, for, instead of the foetal head being found fixed or resting on the brim of the pelvis, as is to be found in all illustrated representations of this opcration, we should find it moveable, and the moment we toush it with a perforator it recedes, and we should have literilly to bore through the calvarium, with no fixed or antagonistic power; and there would be no projections, chasms, or sutures to guide and direct us where to make the opening, but we should have to contend with the hard thick layers of bony deposit, which could only be controlled by an assistant lieeping firm pressure abore the umbilical region of the mother's abdomen. After making this opening, we shall require what Dr. Davies calls his osteotomist, a powerful and most useful instrument for breaking down cranial bones. In perforating the foetal head, we should endeavour to dircet the point of the perforator to the base of the brain, in order to ensure the destruction of vitality. I have never heard the child cry in utero; but I have heard one make a most frightful noise after the head has been broken down and the brain smashed by the operation of craniotomy, while the body was still lying in the passage. Fortunately, the bedelothes drowned the sound, but it producerl such a very peculiar sensation on the tympanum of my ears, and the gentleman that was with me, that neither of us will ever forget it.

When we have opened the head, some authors tell us that we should leave the natural pains to complete the labour. But this, in my opinion, would, in these cases, be bad practice. Having begun to interfere, we should complete the labour: to wait, would only be prolonging the patient's misery. For, after such highly ossified skulls are perforated, it does not follow that they collapse or become lessened in size, like an hydrocephalic head, or one less.firm in texture. Those who recommend such a practice must have forgotten that long distension, and an unusually high degree of tension, will have the effect of weakening the expulsive power of such a muscular organ, and is likely to produce an atonic condition of the uterus. This is well known by those who have often been called on to perform this trying and mutilating operation ; for we have to break it down and bring it away by piecemeal. All writers on operative midwifery have given us ample directions and admonitions, for our guidance as to the dimensions of the outlet of the pelvis, and the size of the foetal head, but no allusion to its texture. I fear, were we to attend to all their advice, and directions as to measurement, it would involve a certain amount of delay, which would most certainly be incurring risk, as well as jeopardising the life of the mother. If ever a woman dies from the operation of cmbryotomy or craniotomy having been performed on the fotus in utero, it must be entirely in consequence of the effects produced on her constitution, from the head bcing impacted in the superior outlet of the pelvis, and by delaying the operation too long. If this peration be timely and properly performed, the practised accoucheur would never have any scrious apprchensions for the safety of the mother, or his own reputation.

I believe it has been recommended by a professor of midwifery that we should wait for the death of the child before we make up our mind to operate; but this would be a painful and useless exercise of patience and forbearance. The stethoscope and auscnltation are recommended, to enable us to ascertain the fact. This would be, in my opinion, awful practice, and tritling with the valuable life intrusted to our care. In cases of a hirh degrec of ossification of the fortal head, and it is to this altered state of the head our energies must be all applied, we must pay no attention to the size of the pelvis, nor to the stethoscopic diagnosis. All cur attention is to be directed to the condition of the head of the child; for here is an unusual large bony conformation of unyiclding matter, incapable of adapting itself to the outlet of the pelvis: and all the natural uterine expulsive efforts of the mother to give birth to the child must be fruitless and impracticable; and those continued efforts of the mother to mould and adapt the child's head to the outlet may go on for hours, and even days, without causing dcath, or injury to the child. But the continued pressure and bumping on the soft parts of the brim of the pelvis would very soon produce inflammation and fatal consequences to the mother; therefore, to wait for the death of the child before we attempt to deliver, would be being accessory to the death of the mother; such practice, then, cannot be countenanced, and ought never to be adopted.

To enable us to be cognisable of auscultatory sounds, requires the greatest nicety of ear, and adroitness in examination, as well as patience in renewing the examination. But this is, certainly, not the time for the exercise of patience, nor practising the ear to sounds, or preparing us to become stethoscopists. All men do not possess delicacy of hearing, nor have they musical ears; they would, consequently, be as much puzzled by these stethoscopic observations as to the pulsatory sounds of the foetal heart, as they would be to decide what was harmony and what was discord in music. 'lo adopt such a practice, except by practised auscultators, would be deceiving themselves and the patient.

The child, in utero, would retain the vital spark longer than the matcrnal constitution would hold out; while the long continued uterine expulsive efforts of the mother would have no serious effect on the child. The great sceret is to know how and when to act: could we judge with certainty of the death of the child in utero, it would be, indeed, a happy circumstance.

The late Mr. Brookes, in his lectures to his pupils on operative surgery, used to tell them, when operating on the dead body, they were to fancy it a living subject. In this case, the reverse would be my advice. We are not, in these cases, merely to decide which would be the most appropriate mode, or what operation would be the safest for us to have 
recourse to, in order to meet or orercome those protracted or dificult labours; but it is one of far higher importance and of much greater consideration. We have to muster all our moral courage to make up our minds to coolly and deliberately take away the life of a human being. This is a most trying and painful position to be placed in, and it is a cruel and deplorable case of professional expediency ; but duty compels us, and we must act, as our vocation imposes on us this peculiar and distressing duty. Much has been written and said about the moral obligation and the responsibility of our situation in reference to this operation. I do not see why medical men should be suspected of want of feeling, or indifference, in those cases of duty and trial, when our skill and judgment are to be tested and called into action. I trust that none of us ever forget our moral or religious obligations, and that, on those occasions, we are only instruments in the hands of $\mathrm{Him}$ who is the giver as well as the preserver of life, in our responsibility to our patients; but must, more or less, be deeply impressed by the circumstances and the situation in which we are placed, as the medical attendant, having intrusted to our care and attention, by, perhaps, an affectionate and attached husband, a most beloved wife, and an endeared mother, whose children, though they may be unconscious of her situation and danger, are waiting for her recovery and anxiously expecting her return to her domestic duties. Surely, such a mother's life and such a family demand all our attention and sympathy. We are not only bound by our professional duty, but humanity would prompt us to aid and relieve such an endearing object; and such a life, surely, must be infinitely of more value than that of an unborn child. To save such a life must be all our anxiety and sole aim; this can only be done, when there is a large ossified cranium, by an early reduction of its size, and we have no other remedy. I am quite sure that no respectable accoucheur would rashly have recourse to such a fatal operation, unless driven to it by the strongest and most painful necessity ; nor would it be justifiable in him until all hope shall have been extinguished of the competency of the natural powers to effect the delivery, and the condition of the cranial bones being fully and com pletely ascertained; the latter is of great importance, and this call only be known by the touch, or taking, and trying a pain as it is called. Although this mode of determining the state and situation of the parts is designated by the French le toucher, we have no term by which to express this but the one I have used, which is understood and familiar both to nurse and patient. The touch may be considered a very obscure sense compared to the sight; but it is the eye of the accoucheur, and it may, by use, be made to equal it. In operative midwifery it is our sheet anchor ; and it is this index and a small hand that cnable us to distinguish the state and condition of the presenting parts and by the exercise of this sense we can only ascertain and judge of what is going on. When, on examination, we discover that there is a large head, and a high degree of ossification, we must also expect to find the uterus high up abore the brim of the pelvis, and the neck distended over the whole head, like a thin membranc, presenting to the finger a hard smooth surface, which, on pressure being applicd, recedes; the os uteri is also thin, and scarcely to be distinguished, and generally dilated about the size of a shilling, and there may be a slight discharge of liquor amnii the membranes being so much distended, they may have given way, but the quantity of water that escapes would be very trifling, the head acting as a plug. This keeping back of the waters tends to keep the uterus in a buoyant state, and likewise supports the fotus, and this, I consider, is the cause of the child being generally found alive; as the head of the child, in those cases, cannot, from its ossified condition, effect an entry into the pelvis. This natural instrument of dilatation, viz., the foetal head, cannot exert its usual, avd properly dilating powers upon the os uteri, however long we may defer or delay the operation. The obstetric practitioner has generally much faith, and calcuIates greatly on time and nature, and often relies on it to accomplish the delivery; but here time would be lost, and,
Tithont manul senistance, nature would be coces exhanated.

Having ascertained the coudition of the footal head, and being fully atisfied of the improbability and imposcibility of its adapting itoelf to the outlet of the polvis, by the natural efforts of the mother; we have no other reovures but to reduce the size of the head. After duly inrestigating all the circumstances, and every point connected with it, we have ouly to determine on the operttion; so that upon reflection, afterwards, we may foel quite free from compunction or self reproach. All that will be required is a certain amount of self command and moral courage, with a thorough knowledge of the vaginal passage, the pelvic cavity, and the situation of the iterus. $A$ timid and nerrous practitioner may be unnerved and terrified at the thought of the operation. Such a man should not attempt it ; most certainly not by himself. I have operated frequently myself, with only the nurse and a female friend being present as a general rule. I should say that such an operation ought never to be performed alone, unless the operator had some practice, and had the entire confidence of the patient and her relatives; for, to be placed in a position to decide on the preservation or sacrifice of a life, without the benefit of advice or assistance, is a very serious and responsible situation to be in, and must test both our feclings, skill, and courage. I believe there is no operation that a surgeon is called on to perform which involves such serious effects and awful consequences as embryotomy. Our surgical operative abilities are generally called into action to preserre or to prolong life; but here our only solace is, that, if we do not destroy one life, both would be sacrificed: therefore, we can condole ourselves, and derive much comfort from the assurance, that the life sacrificed was unconscious, and no doubt roid of feeling, perception, idea, pleasure, or pain.

Having, I fear, occupied too much time in describing the presentation of an unusually large ossified fotal head, and its consequences, $I$ will only spend a few moments in describing some of the circumstances in connexion with the operation of reducing the head. As I have said in a former part of this paper, the operation of craniotomy is, in a general way, a simple one; but in the case before us it is more complicated, and somewhat difficult; for here, instead of finding the head of the fotus resting on the brim, or bcing impacted within the outlet of the pelvis, as the illustrated works on operative unidwifery show us when describing this operation, we shall find it still within the utcrus; and the perforating and breaking down of the head must be performed within the uterus itself, before we can get the neck of the uterus over it. The operation is hence rendered one of great nicety and care; for, when we have made an opening into the fotal skull, we have not lessened its diameter; and when we introduce the craniotomy forceps within the uterus, we must take care that we do not mistake the hole we have made through the scalp for the lip of the os uteri, and include it within the tecth of the forceps; for we shall still find the neck of the uterus firmly attached to the head, and very thin; the scalp will also be found unusually thin.

In applying the forceps, one part or blade should be introduced into the opening made in the cranium by the perforator, and the finger directed to the other part; and, before the blade or teeth are brought together, if by the handle a slight push is given, the head will recede suffciently to admit of their closing between the scalp and the neck of the uterus, without injury or entangling the parts; and enable us to break down the bones. Having done this, we shall have but very little difficulty in completing the delivery. Old writers tell us that, before we deliver, wo must scoop out the brains; and, amongst the instruments necessary for the operation of craniotomy, recommended by. Dr. Osmond, is a tablespoon, which, I suppose, is to be used for this purpose. It is strange that any man, who must have had some practice, could ever suppose this process should be necessary, or that such a soft mass as the brain could interfere with the labour after the head had been 
opened. I have never found this scooping to be necessary or advisable. Dr. Blundell tells us that we must convert the brain into a pulp, or, as he terms it, it must be pulpified. I should say that the brains the Doctor met with were something like the cranial bones I am speaking about, rather harder than usual. After the head is broken down, I immediately proceed to bring away the mutilated body; and, I believe, the quicker this is done after the head has been opened, the greater the chance of the patient's recovery. There is nothing to be gained by delay. The blunt hook is the most useful instrument for this purpose. In performing this, I have often felt the want of an instrument with which I could hold fast a portion of the scalp, as well as pieces of bone, without cutting or breaking either; and with both included there would be less risk of lacerating the vagina with the sharp points, or spicula of bones; and also with such an holdfast we could greatly assist the uterine action. I have, therefore, had one made after my own fashion, which I call the operator's assistant.

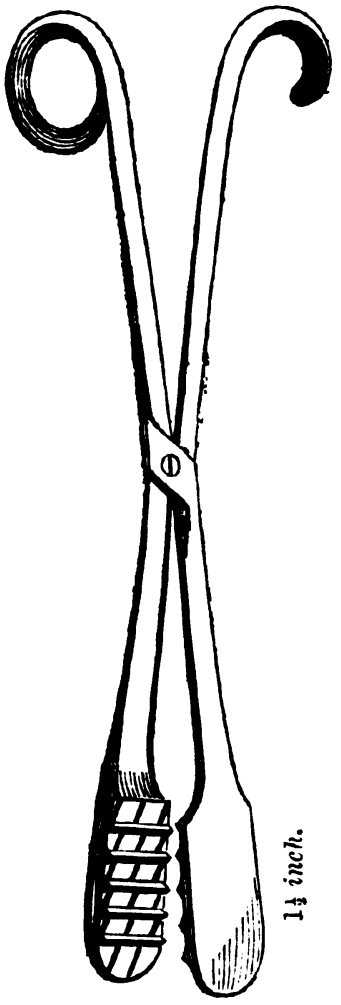

The teeth of those I have seen are in the way, and are apt to get entangled in the membranes; and it is no easy task to disengage them when we wish to withdraw them. This is obviated in the instrument represented above, by having grooves in place of teeth. The hook handle gives greater freedom and liberty to the fingers and hand than the round one. Those who have had much to do with operative midwifery, and particularly craniotomy or embryotomy, must, I am sure, have felt the want of some such instrument. Much is to be done with the hands and fingers in those cases; but they become almost candled by the heat and moisture of the parts, and often, by the length of time employed, become almost useless, and we are obliged to delay the operation in consequence.

We must always bear in mind that the great object that we have in view in performing this operation is to save the patient much useless pain and misery, both of body and mind. And, in rendering this artificial assistance in labours, we must also not forget that nature is in an ordinary way rather slow in her movements, and we should endeavour to follow the ordinary and natural process in our morements, and not be in too much hurry; but, having begun, we should never leave off until the delivery is completed. I have had, during my practice, to attend several times three women with contracted pelvis, with foetal heads not disposed to adapt themselves to the superior outlet : and two of these women had also been attended by other accoucheurs, who had also been obliged to destroy the children. These women, from not having had living children, generally require our services the oftener. This is to be regretted; but it is useless for us to moralise, or to remonstrate with them on the impropriety of their pursuing a course, the certain result and consequence of which must be a murderous operation upon an innocent child, and hazardous to their own lives. And this is not all. It will cause the surgical attendant much extra and anxious labour, as well as painful anxiety for the safety of the patient: and, with a perfect certainty of all these circumstances, and a foreknowledge of such painful and melancholy consequences, it scems to have no subduing influence over the passions of the partes criminales. Notwithstanding the general condition of the foetal head, and great deformity of the pelvis. each of the women has given birth to living and well formed children, at the full period of gestation. One of these patients I prevailed on to allow me to bring on labour between the seventh and eighth months, which I did successfully, and the child is now a fine little girl, near three years old; and in January last I confined the same woman with another living child, after a natural labour of about five hours' duration. She had had four children destroyed by the operation of craniotomy since her marriage. The other woman died after the birth of her fifth child. She was a powerful woman, and her labour pains were always very strong and frequent. I was not sent for till some hours after labour began. Knowing the sort of labours she had before, she thought the time had not come for my interference. On my arrival, I found the head presenting, the os utcri slightly dilated; and there had been a little. discharge of liquor amnii. The uterus rested on the pelvic outlet. There was nothing to create alarm or anxiety; and, as was usually the case with her, she had plenty of energy and power. I left her, and promised to call again in three or four hours, which I did, when I was informed that her pains had left her for near two hours; and she complained of pains in her left side, just above the hip. I was surprised at her prostrate appearance, and gave 3 ss tinct. opii in brandy and water. As the pains had left, and there was no advancement in the labour, I saw no chance of her being able to give birth to the child. I returned for my instruments, and reduced the size of the head, and delivered her. There was no hamorrhage either before or after the delivery, and, in fact, nothing to account for the sudden suppression of the pains, and the otheralarming symptoms. The removing the child did not improve her condition, although she bore the operation very well, and at first seemed to revive; but she did not rally, and died about fifteen hours after the delivery. A post mortem examination, the following day, explained the whole matter. We found a rent in the uterus, about two inches long, between the broad ligament and the neck, and externally to it there was a large clot of blood lying in the superior cavity of the pelvis. This rupture or giving way of the uterus was, I have no doubt, the consequence of the unyielding and ossified condition of the foctal head, and the very strong expulsive pains. She was seen before death by two of my medical friends, and I was assisted in the post mortem examination by Dr. Edwards, who was then residing in Bath. There was nothing remarkable in the appearance of either of these women; they wcre hoth what would be termed fine grown women. No visible sign of any deformity; and I should class their pelves among the contracted, not the deformed. In both cases, the foetal head was at fault more than the pelvis.

Since I gave notice that I should bring the subject forward, I have attended a poor little emaciated deformed woman, with a remarkably contracted pelvic outlet, with her second child. With the first, embryotomy was performed. Her case had produced such a sensation in the 
neighbourbood, that she had some difficulty in getting 2 che had spoken to two, but both surgeon to attend her. She had shis I did not know until I was engaged; but, to their mortification and my surprise I was engaged; but, to theible sized living child, at the full period of gestation. This, I believe, was entirely in consequence of its being a breech presentation and a yielding quence of its being a breech presentation and about fourteen hours.

This ossified condition of the fotal head, I should state, is

This ossified condition of not of frequent occurreace; an of midwifery practice might have never met with such a case. I should say, from my own observation, that the arerage number would be about one in 500 . In my own practice, I have had to perform the operation of craniotomy about fifteen times in upwards of 3,000 cases; but all of them were not in consequence of the ossified condition of the head of the child. Although theso cases are rarely met with in practice, that is no reason why they should be entirely overlooked, and passed over unnoticed when they do occur in connexion with deformity of the pelvis and the operation of craniotomy.

I ought not to close this paper without stating that there may be small ossified foctal heads as well as large ones. As a proof of this, there are cases on record of children's heads having been fractured at the birth; the child having been expelled with the violent and rapid labour pains, while the woman was standing, or leaning on a chair, and the child dropping on the floor. Such an accident as this could never have occurred unless the cranial bones were highly ossified; an osseous cartilaginous cranium would never crack, even were the umbilical cord to give way.

This is a subject of interest and of immense importance in medical jurisprudence; and we, as medical men, when examined in cases of infanticide, should be able to explain and state that this state, condition, and texture of the fotal head, at the time of birth, is sometimes to be met with. It is well known that osseous matter may be dcposited, and that ossification may go on within the cavity of the uterus; and the uterus itself has been found ossified. There is also a case recorded of an ossified foetus and uterus being found in a woinan sixty years old. According to Professor Rokitansky of Vienna, it seems there is a larger proportion of osseous matter in breeding women than others. He says, " that a calcareous deposit has bcen almost constantly found in the internal surface of the skulls of women in the pregnant and puerperal state; and that the skulls become permanently thickened by frequent pregnancies." May not this superabundance of calcareous matter in the mother's system be conveyed to the foctus in utero, and be deposited in the skull, and be the cause of the remarkable degree of firmness I have noticed ?

Bath, October 1553 .

\section{BIBIIOGRAPHICAL NOTICES.}

Expository Lexicon of the Terms, Ancient and Modern, in Medical and Geveral Science; including a complete Medical and Medico-Legal Vocabulary. By $\mathbf{R}$. G. MAYNe, M.D. Part I. pp. 152. London: 1853.

We have very carefully examined the first part of Dr. Marne's Lexicon; and we have great pleasure in expressing our high and unqualified admiration of the manner in which it is executed. From the comprehensive character of the plan which the author has adopted, this Lexicon is suited to the requirements of every educated gentleman. It embraces "the correct pronunciation, derivation, definition, and application of the names, analogues, synonymes, and phrases (in English, Latin, Greek, French, and German,) connected with medicine, and employed in anatomy, astronomy, botany, chemistry, comparative anatomy, conchology, crystalography, entomology, geography, geology, geometry, ichthyology, materia medica, medical jurisprudence, microscopy, mineralogy, history, natural philosophy, noeology, obstetricy, ornitholog, pathologj, pharmacy, phronoology, obstetricy, ornithory, trigonometry, and zoology." We hope that the extraordinary industry and erudition displayed in this work may be rewarded by an extensive displayed in this work mas be rewarded the medical professale. While it is peculiarly adapted to the medical profas as well as to lawyers and coroners.

Prixctples of Soraery. By James Mihler, F.R.S.E. Surgeon in Ordinary to the Queen for Scotland; and Professor of Surgery in the University of Edinburgh. Third edition: illustrated by 240 engravings on wood. 8vo. pp. 760. Edinburgh: 1853.

Thus new edition of Professor MiLner's classical work presents itself in an improved form. As its merits are generally. known and deservedly appreciated, a critical examination known and deservedly appreciated, a critical examer, that Mr. is not required from us. Surgery" is a work of the highest Miller's "Principles of Surgery" self to be equally sound and scientific in his modical treatment, and in his surgical practice. The constitutional character of local discases is judiciously and practically. treated; and the preeminence of conservative over destructive surgery is constantly maintained.

\section{PERISCOPIC REVIEW.}

\section{MIDWIFERT AND DISEASES OF WOMERT.}

RUPTURE OF THE UTERUS:-RFCOVERY.

The following case is recorded by Dr. Thomas Christie, of Lachate, Canada West, in the Canada Medical Journal for February 1853.

On the morning of the 21st August, 185:, he was summoned to attend Mrs. M. during her sixth accouchement. On arrival, he ascertained from the midivife that the patient had been in labour twenty-four hours; the pains had been regular, but not severe; the membranes had ruptured a few hours prior to his arrival; the head had advanced so far as to press on the perinaum: just when she expected that another pain would. have effected delivery, the patient felt something give way: since then the child's head had receded, so that it could not now be felt, and the pains were suspendecl.

Dr. Christie found the patient in bed, with her shoulders raised by an attendant; her face was pale and ghastly, with an expression of intense suffering and anxiety; the pulse was rapid and feeble, and the respiration dillicult. 'The expulsive efforts had entirely ceased. Dr. Christie found a large rupture. in the front of the uterus, through which the body of the child had escaped into the abdomen, the head still remaining in the uterus. Passing on his hand through the laceration, he succceded, after a little search, in laving hold of one of the feet, and ceffected cersion and delivery without difficulty. The child was. dead. After delivery, the patient was attacked with severe vomiting. A large dose of laudanum was administered. At the end of three hours, she anpeared to be better. Dr. Christic then left her, prescribing thirty drops of laudanum three times a day.

August 22nd. She was much stronger, and had dozed almost censtantly. He prescribed twenty drops of tincture of opium three times a day.

August 24th. He found her much worse. The pulse had taken on the inflammatory character; the tongue was coated; the ubdomen extremely tender, and much distended. He bled her largely, and ordered eight grains of calomel and one of opium to be given three times a day, and a large blister to be appliel to the abdomen.

August 25th. She was still worse; the pulse was 130; the tongue was brown and coated; the countenance anxious and pinched; she had hiccup and vomiting. Hot fomentations were applied to the abdomen, and calomel and opium were given every four hours.

Augnst 26th. The calomel was omitted; the opium con. tinued. She gradually made a perfect recovery. 